\title{
Implikasi Metode Belajar Bersama Alam Di School Of Universe
}

\author{
Nanda Ayu Setiawati ${ }^{1}$ \\ 1UNIMED, Medan, Indonesia
}

Corresponding Author: $\otimes$ nandaayusetiawati04@gmail.com

\begin{tabular}{|c|c|}
\hline & ABSTRACT \\
\hline $\begin{array}{l}\text { ARTICLE INFO } \\
\text { Article history: } \\
\text { Received } \\
12 \text { October } 2020 \\
\text { Revised } \\
24 \text { October } 2020 \\
\text { Accepted } \\
25 \text { October } 2020\end{array}$ & $\begin{array}{l}\text { Indonesia merupakan negara yang memiliki keanekaragaman hayati } \\
\text { terbanyak di dunia setelah Brasil. Kekayaan itu yang menyebabkan } \\
\text { Indonesia menempati posisi penting dalam peta keanekargaman hayati } \\
\text { dunia dan dikenal sebagai salah satu Megabiodiversity Country. Penelitian } \\
\text { ini bertujuan untuk mendeskripsikan pelaksanaan Metode belajar } \\
\text { bersama alam di School of Univere. Penelitian menggunakan pendekatan } \\
\text { kualitatif.Teknik pengumpul data yang dilakukan dalam penelitian ini } \\
\text { adalah:wawancara, observasi serta dokumentasi. Analisis data dalam } \\
\text { penelitian ini menggunakan model interaktif Miles dan Huberman, } \\
\text { adapun langkah-langkah yang ditempuh seperti reduksi data, model } \\
\text { data, kesimpulan dan melakukan verifikasi. Hasil penelitian ini } \\
\text { dianjurkan dapat diterapkan di sekolah konvensional, dengan cara } \\
\text { mengakolaborasi kurikulum dan model pembelajaran khas School of } \\
\text { Universe. Metode belajar bersamaalam berupaya mendekatkan peserta } \\
\text { didik dengan alam,merawat kelestarian lingkungan, dan belajar untuk } \\
\text { menjaga lingkungan alam, Belajar bersama alam (BBA) dalam } \\
\text { implementasinya terkait KBM meliputi (1) Seolah yang menggunakan } \\
\text { potensi sumber daya lingkungan sebagai media utama dalam } \\
\text { pembelajaran, ciri utamanya adalah greenlab sebagai tumpuan KBM, (2) } \\
\text { Aktivitas belajar dari pengalaman adalah aktivitas utama dalam proses } \\
\text { KB M, dtandai dengan para guru sebagai pendidik yang punya } \\
\text { karaktersenang bereksperimen, (3) Pembelajaran yang khas sekolah alam } \\
\text { (eksplorasi, eksperimen, eksploitasi SDL, culture, dan outing adalah } \\
\text { metode utama dalam penyampaian KBM beajar bersama alam. }\end{array}$ \\
\hline Keywords & $\begin{array}{l}\text { Metode belajar bersama alam, Sikap peduli lingkungan, School of } \\
\text { Universe }\end{array}$ \\
\hline How to cite & $\begin{array}{l}\text { Name. (2020). Tittle. Journal Continuous Education, 1(1). 36-42. } \\
\text { http://pusdikra-publishing.com/index.php/josr/issue/current }\end{array}$ \\
\hline
\end{tabular}

\section{PENDAHULUAN}

Setiap daerah menjadi tempat yang terbaik untuk setiap potensinya masing-masing. Sudah saatnya peserta didik diajak merawat, memperlajari, hingga mampu menggunakan SDA dengan baik. Bukan sekedar teori tetapi sekaligus keterampilan dalam mengelola sumber daya daerah.Dengan belajar bersama alam peserta didik mempunyai bekal yang paling cukup atas daerahya sendiri.Belajar untuk menggunakan potensi daerah dengan optimal dan bijak. 
Ini adalah ilmu yang sangat mahal karena jarang, padahal kehadiran ilmu seperti ini adalah wajib.

Ketika sistem pendidikan yang ada lebih menekankan kepada nilai dan anga-angka bukannya kepada karakter/akhlak, dengan "menyamakan" cara dan bahan ajar untuk setiap peserta didik di setiap wilayah, maka setiap penambahan kelulusan akan semakin menambah pengangguran. Menyeragamkan sesuatu yang dari "sana" nya sudah diciptakan berbeda untuk saling memberikan rahmat akan menghapus potensi keunikan hingga potensi bangsa ini akan tiada.

Sekolah alam adalah salah satu bentuk dari pendidikan alternatif dalam menghadapi sekolah konvensional. Pendidikan alternatif bertujuan sebagai wahana untuk mengubah mental anak-anak dan remaja agar menjadi anak bangsa yang dinamis aktif kreatif terbuka dan produktif serta memiliki sikap solidaritas sosial yang tinggi terhadap sesama manusia, sesama makhluk ciptaan Tuhan YME,agar terciptanya sikap swadaya, berbudaya, cinta bangsa dan cinta tanah air.

Sekolah alam sangat berbeda dengan sekolah formal, terutama pada metode pembelajaran pada saat proses pembelajaran. Metode pembelajaran sangat menentukan keberhasilan dari proses pembelajaran, bagusnya suatu metode yang dipilih, maka akan memudahkan peserta didik dalam mengingkatkaan hasil belajarnya serta sikapnya dalam kehidupan sehari-hari. Salah satu metode yang digunakan di School of Universe yaitu metode belajar bersama alam.

Salah satu metode yang diterapkan diterapkan di School of Universe yaitu metode belajar bersama alam (BBA).Belajar bersama alam dilmulai dengan semangat insitu development.Indonesia bagaikan untaian Zamrud Khatulistiwa.Istilah ini menggambarkan kekayaan alam negeri ini.Begitu melimpahnya SDA. Secara garis besar SDA terbagi menjadi dua: yang tidak dapat diperbarui (unrenewable) dan yang dapat diperbarui (renewable). Keanekaragaman hayati termasuk dalam SDA yang dapat diperbarui. Potensi SDA hayati tersebut sangat banyak bervariasi, bergantung pada letak kawasannnya

SDA hayati cukup luas, yakni mencakup tumbuhan, hewan, bentang alam,(landscape), dan sosial budaya. Potensi itu bisa berada dalam olahan tangan anak cucu kita.Seharusnya sudah tidak selayaknya hanya sebagai penonton yang melihat orang asing justru menggunakannya. Jika belajar bersama alam dan pendidikan bisnis dilakukan sejak kecil, dan dituntaskan saat remaja, hal ini sangat mungkin terlaksana, dengan cara itu, dunia akan 
kembali belajar kepada Indonesia, seperti zaman sriwijaya dahulu. Sebab, mempunyai semuanya.

Pendidikan harus mempunyai kedudukan strategis dan memegang peran yang penting dalam mempersiapkan sumber daya manusia yang berkualitas. Oleh karena itu, perlunya metode pendidikan yang sesuai dengan kultur masyarakat. Sebab, pendidikan tidak bisa dipaksakan menurut pengelola pendidikan.Sudah saatnya pendidikan di Indonesia memakai dan menggali kurikulum yang mengambil basis potensi lokal. Agar di masa yang akan datang peserta didik paham, giat belajar, dan melestarikan SDA yang ada di lingkungan kehidupannya.

Menurut Freire(1985:51) menyusun daftar antagonisme pendidikan "gaya bank" itu sebagai berikut: (1) guru mengajar, peserta didik belajar; (2) guru tahu segalanya, peserta didik tidak tahu apa-apa; (3) guru berpikir, peserta didik dipikirkan; (4) guru bercerita, peserta didik mendengarkan; (5) guru menentukan peraturan peserta didik diatur; (6) guru memilih dan memaksakan pilihannya, peserta didik menyetujuinya (7) guru berbuat, peserta didik membayangkan dirinya berbuat melalui perbuatan gurunya; (8) guru memilih bahan dan isi pelajaran, peserta didik menyesuaikan diri dengan pelajaran itu; (9) guru mencampuradukkan kewenangan ilmu pengetahuan dan kewenangan jabatannya, yang ia lakukan untuk menghalangi peserta didik; (10) guru adalah subjek proses belajar, peserta didik objeknya.

Illich (1984:15) mengatakan bahwa sekolah tidak mengembangkan kegiatan belajar ataupun mengajarkan keadilan, sebab para guru lebih menekankan pengajaran yang sudah dijadikan paket-paket bersama dengan sertifikat.Belajar sering merupakan hasil dari pengajaran, tetapi seleksi untuk menduduki suatu peran atau jabatan dalam pasar kerja semakin tergantung pada sekedar lama tidaknya mengikuti pendidikan di sekolah.Illichjuga mengkritik (dalam Yusnadi, 2018:131) peranan tradisional seorang guru bahwa guru menghadapi peserta didik dapat meniadikan rasa aman bagi kemerdekaan peserta didik. Guru berfungsi sebagai hakim peserta didik.

Menurut Tilaar (dalam Hatimah, 2016:37) beberapa butir pokok penddidikan yang dikemukakan oleh Ki Hajar Dewantoro adalah:

1. Bahwa kebudayaan tidak dapat dipisahkan dari pendidikan

2. Kebudayaan yang menjadi alasan pendidikan tersebut haruslah bersifat kebangsaan

3. Pendidikan mempunyai arah yaitu untuk mewujudkan keperluan perikehidupan.

4. Arah tujuan pendidikan ialah untuk mengangkat derajat negara dan rakyat

5. Pendidikan yang visioner.

Sekolah bagi peserta didik dan guru merupakan tempat yang setiap hari dikunjungi dan mungkin bagi beberapa kalangan guru dan peserta didi menjadikan sekolah sebagai rumah kedua.Menurut Tatang (2015:16)" sekolah 
merupakan lembaga pendidikan, yaitu lingkungan tempat terjadinya berbagai aktivitas pendidikan, baik proses, pembelajaran maupun evaluasi pendidikan".lingkungan tempat terjadinya aktivitas pendidikan dapat diartikan sebagai lingkungan yang berpengaruh terhadap praktek pendidikan

Sumardi (2005:77) mengatakan konsep pendidikan alternatif pada dasarnya bertitik tolak dari filsafat alam dan filsafat budaya, yang beranggapan bahwa manusia dan alam merupakan ciptaan Tuhan yang paling berharga dan bernilai di dunia ini.Salah satu pendidikan alternatif yakni sekolah alam. Hal ini sejalan dengan pendapat oleh Lendonovo (2018:10) bahwasannya "sekolah alam adalah sebuah konsep pendidikan yang digagas oleh Lendonovo berdasarkan keprihatinannya akan biaya pendidikan yang semakin tidak terjangkau oleh masyarakat".

Pendidikan alternatif berupa Sekolah alam memiliki kelebihan. Menurut Santoso (2010:13-18), kelebihan-kelebihan pada sekolah alam yang bisa dibuktikan adalah sebagai berikut:

a. Sekolah alam cenderung membebaskan keinginan kreatif peserta didik

b. Konsep pembelajaran dengan cara sambil bermain

c. Guru atau tenaga pengajar sekolah berbasis alam yang baik tentu saja tetap merupakan mahasiswa/lulusan perguruan tinggi negeri (PTN)

d. Metodologi pembelajaran yang diterapkan cenderung mengarah pada pencapaian logika berpikir dan inovasi

e. Bagi Sekolah alam yang memang dikelola oleh pihak swasta atau lembaga tertentu yang kredibel

f. Yang menarik di Sekolah alam, tidak hanya peserta didik yang belajar. Guru pun dituntut untuk terus belajar

g. Sekolah yang berbasis alam pastilah dilingkupi berbagai macam pepohonan yang ada di sekitarnya

h. Materi pembelajaran tentu saja disesuaikan dengan kompetensi kurikulum pada rentang waktu tertentu dan terprogram secara matang

i. Untuk mengukur sejauh mana inovasi peserta didik diterima publik, maka sekali dalam satu semester (enam bulan sekali), biasanya diadakan evaluasi.

Dalam kehidupan sehari-hari manusia secara bijak memanfaatkan dan menjaga alam semesta untuk kelangsungan kehidupannya.Sumardi (2005:49) "UNESCO merupakan badan yang diusulkan untuk dijadikan acuan sebagai badan pengelola pendidikan negara di dunia, yakni belajar menguasai ilmu pengetahuan, keterampilan, hidup bersama, dan mengenal diri sendiri. Keempat pilar ini perlu dipadukan dengan yang lain sehingga terwujud manusia yang utuh dan dapat memantapkan keberadaannya, menjaga kelangsungan hidup, dan memanfaatkan alam semesta". 
Journal Continuous Education

Volume 1, Issue 1, November 2020

Page 36-42

\section{METODOLOGI PENELITIAN}

Penelitian ini akan dilaksanakan di Sekolah Alam SoU (School of Universe) di Kecamatan Parung, Kabupaten Bogor, Provinsi Jawa Barat.Subjek dalam penelitian ini adalah: Guru kelas 1 sampai 6sekolahdasar. Sekolahalam di School of Universe, siswakelas 1 sampaikelas 6 sekolahdasar.Sekolahalam di School of Universe, KepalaSekolah, Penggagas Sekolah Alam School of Universe. Dalam penelitian ini teknik pengambilan sampelnyadengancara menggunakan purposive samplin. Jenis penelitian yang digunakan dalam penelitian ini adalah penelitian kualitatif.Teknik pengumpul data yang dilakukan dalam penelitian ini adalah sebagai berikut: wawancara, observasi, serta dokumentasi. Analisis data dalam penelitian ini menggunakan model interaktif Miles dan Huberman (dalam Emzir, 2016, 129-133). Langkah-langkahnya sebagai berikut: reduksi data, model data (data display), kesimpulan dan verifikasi.

\section{HASIL PENELITIAN DAN PEMBAHASAN}

Alam pada kata sekolah alam mempunyai dua makna yaitu alam sebagai pengalaman dan alam alam sebagai semesta alam, makhluk, segala sesuatu yang diciptakan Tuhan Yang Maha Esa. Pada proses pembelajarannya sekolah alam selalu mengedepankan bahwa pengalaman adalah guru yang terbaik. Pengalaman menggali alam semesta, makhluk dan segala sesuatu yang ada disekitarnya maupun berbagai kejadian yang ada disekitarnya.Sekolah alam menyebutnya dengan metode belajar bersama alam (BBA). BBA terbagi atas 4 cara: In-Situ Development (pengembangan potensi daerah, Local Resources (Penggalian SDA yaitu menggali potensi yang ada di sekolah dan di daerah sekitar sekolah), Exploring and Experimenting (eksplorasi dan percobaan ilmiah), Indonesian Culture Heritage(Penggalian budaya dan karifan local Indonesia)".

Berdasarkan dokumen dari School of Universe ada pembagian penggalian budaya dan kearifan lokal setiap kelas, sebagai berikut:

Tabel Penggalian Budaya dan Kearifan Lokal di School of Universe

\begin{tabular}{|l|l|l|}
\hline \multicolumn{1}{|c|}{ Level } & \multicolumn{1}{|c|}{ Detail kativitas } & \multicolumn{1}{|c|}{ Integrasi/korelasi } \\
\hline SD 1 dan SD 2 & $\begin{array}{l}\text { - Indonesia dan tarian daerah } \\
\text { - Ragam tarian Minang }\end{array}$ & Bahasa sosial \\
& - Dua permaiann tradisonal minang & Matematika, bahasa, Sains \\
\hline SD 3 dan SD 4 & - Pahlawan dari Sumatera Barat & Bahasa social \\
& - Bela diri asal Sumatera Barat & Bahasa social \\
& • Tempat wisata daerah Sumatera & Bahasa sosial, bisnis \\
& Barat & \\
& Beberapa bangunan bersejerah & Bahasa sosial \\
\hline
\end{tabular}

Berdasrkan hasil observasi adanya kegiatan sains projek merupakan salah satu kegiatan penerapan metode belajar bersama alam.Sains merupakan 
Journal Continuous Education

Volume 1, Issue 1, November 2020

Page 36-42

suatu hal yang penting untuk dipelajari oleh setiap manusia. Logika berpikir manusia akan semakin berkembang dalam proses pembelajaran sains. Semakin berkembangnya kemampuan dalam berpikir logis semakin terampil pula manusia dalam menyelesaikan permasalahan dalam kehidupannya sehari-hari. Kemampuan berpikir saintifik sangat penting dilatih sejak usia dini atau masa kanak-kanak. Hal ini disebabkan rasa keingintahuan (inquiry) peserta didik sedang berkembang secara pesat.Anak-anak banyak melakukan eksplorasi terhadap segala sesuatu yang ada di lingkungan peserta didik.

Sekolah alam sebagai lembaga pendidikan yang memiliki tujuan utama dalam membentuk manusia yang memiliki kemampuan berfikir logis dengan menggunakan media alam semesta menjadikan kegiatan sains projek sebagai kegiatan pembelajaran rutin yang dilakukan setiap semesternya

Green lab adalah rekayasa lingkungan abiotik dan lingkungan biotik dari potensi daerah setempat yang digunakan sebagai sarana belajar mengajar. Greenlab bisa dikatakan sebagai miniatur daerah tersebut. Tujuan greenlab sebagai tempat untuk praktek langsung dan tempat untuk mengenali potensi daerah terutama SDA.Untuk mengitegrasikan potensi wilayah (alam) ke dalam sebuah kurikulum sekolah, maka potensi-potensi tersebut harus didetailkan ke dalam bentuk tema atau projek.

Skema arah dari pemanfaatn sumber daya alam (SDA) dalam KBM di School of Universe sebagai berikut:

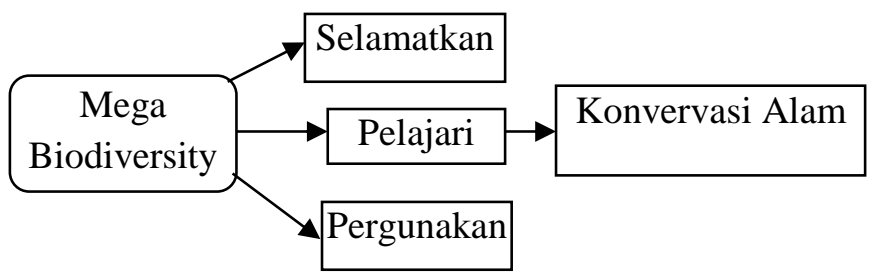

Mega Biodiversity merupakan keanekaragaman hayati yang sanagt besar dan kompleks

* Semangat mengelola alam ini dengan terlebih dahulu menyelamatkan dan melindungi serta mempelajari dan menggunakan sesuai dengan kebutuhan

* Apabila sifat pengelola alam ini demikian, kita dan alam akan harmonis (terjadi keseimbangan/terkonservasi)

\section{UCAPAN TERIMAKASIH}

Terimakasih kepada seluruh pihak yang telah berkenan melakukan penelitian ini, sehingga penelitian yang dilakukan penulis dapat terpublish ke jurnal dan di baca khlayak ramai. 
Journal Continuous Education

Volume 1, Issue 1, November 2020

Page 36-42

\section{REFERENSI}

Emzir.2016. Metodologi Penelitian Kualitatif Ananlisis Data. Jakarta: PT RajaGrafindo Persada.

Freire Paoulo.1972.Pendidikan Kaum Tertindas. Terjemahan oleh Tim Redaksi.(1985). Jakarta: LP3ES

Hatimah Ihat,dkk. 2012. Pembelajaran Berwawasan Kemasyarakatan. Tanggerang Selatan: Universitas Terbuka

Lendo Novo. 2018. 20 Tahun Menggapai Asa dan Mimpi. Bogor: Sou Publisher.

Rohinah.2014. Sekolah Alam Paradigma Baru Pendidikan Islam Humanis.Jurnal Pendidikan Islam, (Online), Vol. 8, No. 2,

(https://www.researchgate.net/publication/305296925_Sekolah_Alam_Pa radigma_Baru_Pendidikan_Islam_Humanis diakses 19 September 2018)

Sumardi, I Sandyawan.2005. Melawan Stigma Melalui Pendidikan Alternatif. Jakarta: Gramedia Widiasarana.

Tatang. 2015. Manajemen Pendidikan Bebrbasis Sekolah. Bandung: Pustaka Setia. 